\title{
Establishing normative foot posture index values for the paediatric population: a cross-sectional study
}

\author{
Gabriel Gijon-Nogueron ${ }^{1 *}$, Jesus Montes-Alguacil', Pilar Alfageme-Garcia², Jose Antonio Cervera-Marin ${ }^{1}$, \\ Jose Miguel Morales-Asencio ${ }^{1}$ and Alfonso Martinez-Nova ${ }^{2}$
}

\begin{abstract}
Background: The Foot Posture Index (FPI) is an observational tool designed to measure the position of the foot. Its reliability is well established, and it provides normative reference values for the general population. However, this is not so for the paediatric population. The aim of this study is to determine FPI reference values in childhood, taking into account age and gender.

Methods: This cross-sectional study included 1,762 school children (863 boys and 899 girls) aged 6-11 years, from Málaga, Granada and Plasencia (Spain). In every case, FPI measurements were obtained for both feet by two experienced podiatrists. A descriptive analysis was then conducted and the percentiles of the variables determined, with a significance level of $P<0.05$.

Results: The consolidated FPI results for the sample population produced mean values of 3.74 (SD 2.93) points for the right foot and 3.83 (SD 2.92) for the left. The 50th percentile was 4 points for both genders and for both feet, except for the right foot among the girls, which was slightly lower, at 3 points. The 85 th percentile, which is considered to represent the boundary between the normal and the pronated foot among children, was 6 points, uniformly among the subjects.

Conclusions: As a normative FPI value for the paediatric population, we recommend the 50th percentile, i.e. 4 points, for children, of both genders, aged 6 years. This value progressively falls with age, to $3 \mathrm{FPI}$ points for children aged 11 years. The 85th percentile for the pronated foot and the 4th percentile for the supinated foot can be considered the pathological boundary.
\end{abstract}

\section{Background}

In recent decades, the question of paediatric asymptomatic and flexible flatfoot (PAFF) has generated much controversy within the scientific community, and the debate continues today [1-5]. It is clear that rigid flatfoot and symptomatic flexible flatfoot (PSFF) in children [6] require proper evaluation [7]. Nevertheless, it is generally agreed that, to a greater or lesser extent, the incidence of PAFF as a physiological condition decreases as the child grows older [8].

\footnotetext{
* Correspondence: gagijon@uma.es

${ }^{1}$ Department of Nursing and Podiatry, Arquitecto Francisco Peñalosa 3, Malaga, Spain

Full list of author information is available at the end of the article
}

Various ways of measuring PAFF have been proposed, ranging from simple examination of the footprint [9-12] to radiographic measures of the angle of the medial longitudinal arch $[13,14]$ to observational tests such as that of the heel rise [15] or the navicular drop [16-18], although few of these have been validated for use with children. As a result, clinicians are forced to make diagnostic decisions based on their personal experience with cases of PAFF [2].

The validation of foot measurement tests for paediatric patients would reduce the risk of errors being made in profiles of clinical normality, and could complement traditional diagnostics methods such as radiology. These tests could even serve as an initial screening method in large-scale analyses, prior to the application of more complex and/or specific tests. 
The Foot Posture Index (FPI) is an observational measurement instrument that takes into account the three-dimensional nature of foot posture and has been shown to achieve good reliability in adults $[19,20]$ and in children [19, 21-23]. It has also been considered an appropriate measure for subjects who are not in good health [24-27]. Reference FPI values have been established for the adult population [20], but during childhood foot posture changes with growth and, to the best of our knowledge, no FPI reference values have been proposed for this population.

In view of the above considerations, the contribution of this study is that we establish normative values for age-related FPI in the paediatric population, with respect to the age group that is most susceptible to changes in foot posture.

\section{Methods \\ Participants}

This cross-sectional study involved 1,762 school children (863 boys and 899 girls) aged 6-11 years. Measurements were taken during 2013 and 2014, at ten schools randomly selected from 25 located in the provinces of Málaga, Granada and Plasencia (Spain). The average age of the sample was 8.29 years (SD 1.72) and the mean BMI of the children was 18.94 (SD $3.65 \mathrm{~kg} / \mathrm{m}^{2}$ ) in the boys and $18.89\left(\mathrm{SD} 3.64 \mathrm{~kg} / \mathrm{m}^{2}\right)$ in the girls. The difference between genders was not statistically significant $(p=0.834)$ (Table 1$)$.

The inclusion criterion was that the children should be 6-11 years old. The exclusion criteria included the presence of pain in the foot at the time of physical examination, injury to the lower limbs, such as musculoskeletal injuries, during the previous 6 months, congenital structural abnormalities, cerebral palsy, motor dysfunction or prior surgery affecting the foot. The parents were previously informed about the characteristics of the study. They were all asked to complete a questionnaire and to provide signed consent to confirm the participation of their children in the study. This study was conducted in accordance with the Declaration of Helsinki and was approved by the Ethics Committees of the Universities of Extremadura and Málaga (Spain).

\section{Procedure}

Foot posture was assessed by measuring the FPI with the subjects barefoot, in a relaxed standing position on a bench at $50 \mathrm{~cm}$ above the floor to facilitate visual and manual inspection. The FPI consists of the following six items referring to the position of the forefoot, midfoot and hindfoot, and the three planes of motion: 1) talar head palpation; 2) symmetry of supra and infra lateral malleolar curvature; 3 ) inversion/eversion of the calcaneus; 4) prominence in the region of the talus-scaphoid joint; 5) height of the medial longitudinal arch; 6) abduction/adduction of the forefoot. The FPI thus obtained ranges from -12 (highly supinated) to +12 (highly pronated) [19]. Inter-observer reliability for the FPI in the paediatric population is reflected in the consistent weighted Kappa value obtained $(\mathrm{Kw}=0.86)$ by Morrison \& Ferrari [22] in a sample of children aged 5-16 years. In our study, the FPI values were measured by two podiatrists (JMA and PAG) who are experienced in the use of this instrument. Both researchers measured the same 30 children and the inter-correlation coefficient (ICC) was calculated by reference to the same sample. Both podiatrists were blinded by using a folding screen, which was placed between the subject and the assessor, and only the foot and $10 \mathrm{~cm}$ of shank were visible. Participants were assessed while in a relaxed standing position, on a bench $50 \mathrm{~cm}$ tall to enable visual and manual inspection. Good inter-observer reliability was recorded (I.C.C. 0.852-0.895).

In all other respects of measurement, the protocol described by Redmond et al. in their manual for the FPI [28] was used.

\section{Data analysis}

Statistical analysis was performed with SPSS.22 Software (SPSS Inc., USA). After checking the normality of the distribution (Kolmogorov-Smirnov) and the homogeneity of the data (Levene) in both samples, descriptive statistics were used to characterise the sample. The FPI was also analysed as continuous data rather than as z-score data [19]. A descriptive and frequency analysis of the variables was conducted, and the means, standard deviation and percentiles were determined. Student's T-test was used as inferential proof

Table 1 Descriptive for age, weight, height and BMI of the entire sample by gender

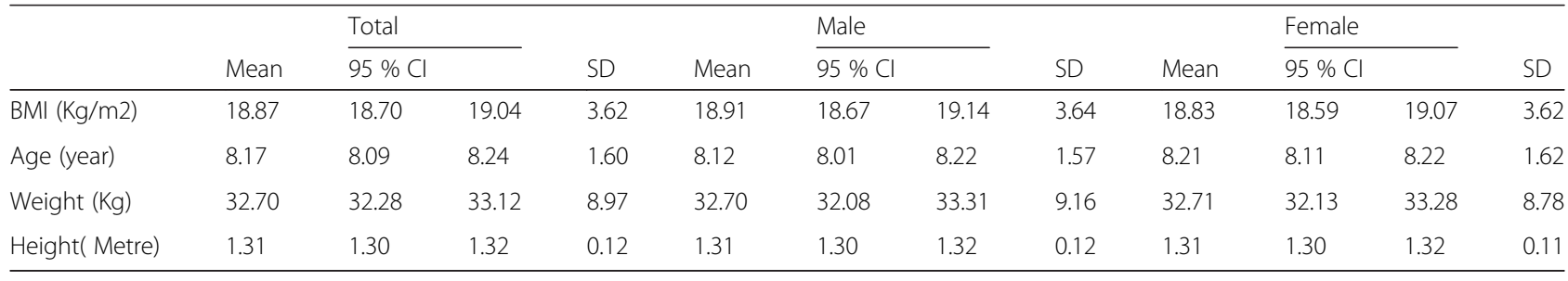


Table 2 Descriptions for the FPI of the whole sample. Detailed separate items, laterality and gender

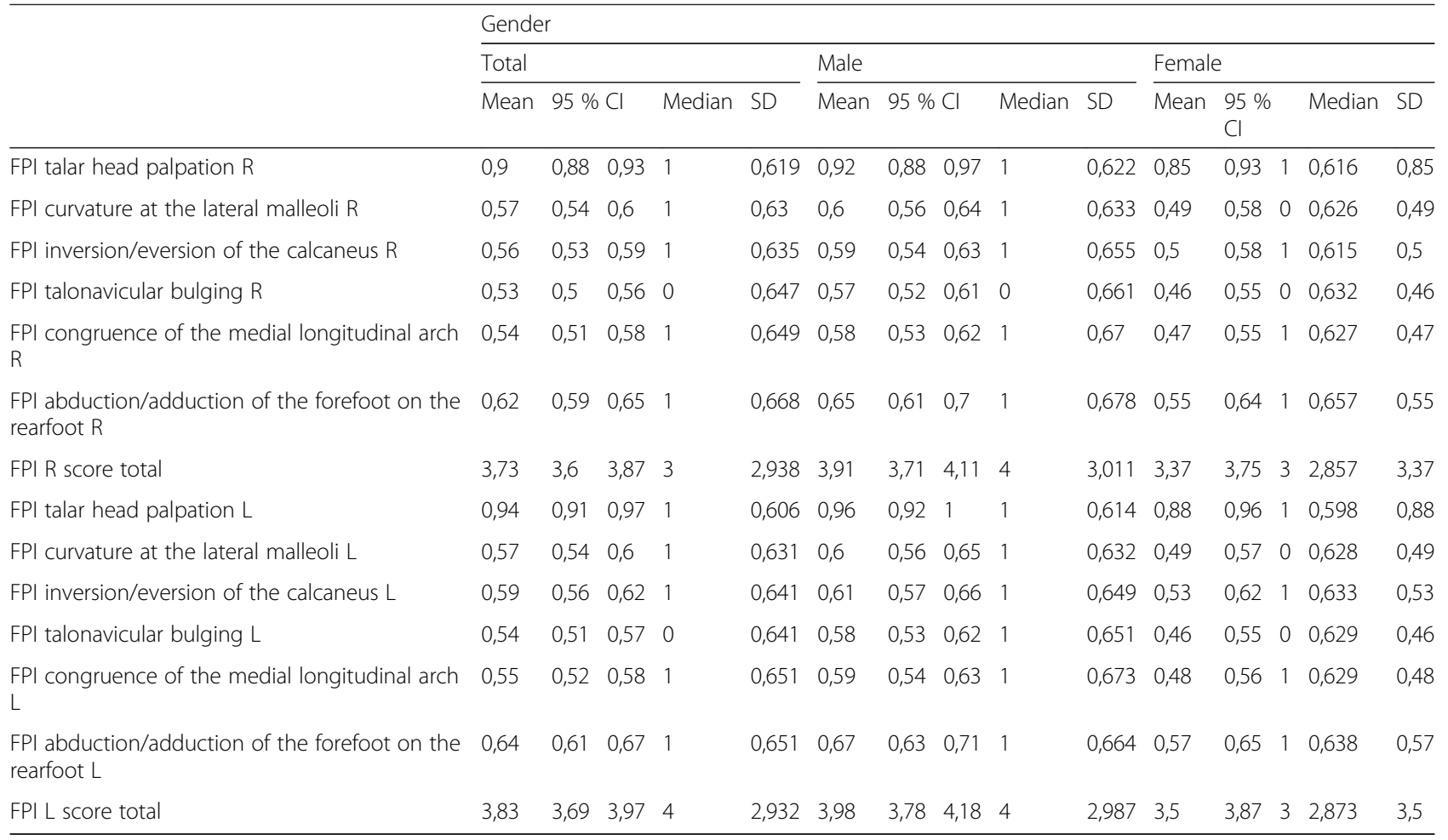

for related samples (FPI, gender and age). The level of statistical significance was set at $p<0.05$.

\section{Results and discussion}

For the whole sample, the mean FPI obtained was 3.77 points (SD 2.93) for the right foot and 3.87 points (SD 2.92) for the left foot. By gender, the average values for the right foot were slightly higher in the boys than in the girls, with values of 3.93 (SD 2.99) versus 3.61 (SD $2.86)$, respectively, and the difference was statistically significant $(p=0.026)$. The mean values for the left foot were 4.00 (SD 2.96) in the boys and 3.74 (SD 2.87) in the girls (Table 2).

By age groups, statistically significant differences between the genders $(p<0.05)$ were only observed in the children aged 6 years (right foot) and 7-12 years (left foot) (Table 3).

The FPI values were distributed into percentiles, as a continuous variable. A mean value of 4 points was obtained for the 50th percentile in both genders and for both feet, except the right foot in the girls, for which the value was slightly lower, at 3 points. The 75 th sample produced uniform results, with 6 points in every case, and this value is considered the dividing line between physiological and pathological pronation. The mean FPI values and percentiles obtained for children aged 6-11 years are shown in four graphs, one for each gender and foot (see Figs. 1 and 2). In these graphs, the 50th percentiles are represented by the thick black line, the 25th percentiles by the thick red line and the 75th percentiles by the thick brown line, while thin lines represent the 90th (pink), 95th (dark blue), 10th (dark grey) and 5th (light blue) percentiles.

Table 3 Total FPI scores by age and laterality

\begin{tabular}{|c|c|c|c|c|c|c|}
\hline \multirow[b]{2}{*}{ Age } & \multirow[b]{2}{*}{ Lateral } & \multicolumn{2}{|l|}{$\mathrm{N}$} & \multicolumn{2}{|c|}{ Mean (SD) } & \multirow[t]{2}{*}{$P$ value } \\
\hline & & Male & Female & Male & Female & \\
\hline \multirow[t]{2}{*}{6} & Right & 128 & 126 & $4.8(2.9)$ & $4.1(2.8)$ & $<0.05$ \\
\hline & Left & 128 & 126 & $5.0(2.9)$ & $4.2(2.7)$ & 0.068 \\
\hline \multirow[t]{2}{*}{7} & Right & 169 & 188 & $4.3(2.9)$ & $3.7(3.0)$ & 0.086 \\
\hline & Left & 169 & 188 & $4.4(2.8)$ & $3.7(3.1)$ & $<0.05$ \\
\hline \multirow[t]{2}{*}{8} & Right & 196 & 166 & $4.1(3.1)$ & $3.8(2.7)$ & 0.383 \\
\hline & Left & 196 & 166 & $4.0(3.0)$ & $3.9(2.8)$ & 0.523 \\
\hline \multirow[t]{2}{*}{9} & Right & 128 & 135 & $3.3(2.9)$ & $3.2(2.8)$ & 0.792 \\
\hline & Left & 128 & 135 & $3.3(2.8)$ & $3.4(2.8)$ & 0.728 \\
\hline \multirow[t]{2}{*}{10} & Right & 113 & 143 & $3.2(2.8)$ & $3.4(2.8)$ & 0.515 \\
\hline & Left & 113 & 143 & $3.3(2.8)$ & $3.6(2.9)$ & 0.301 \\
\hline \multirow[t]{2}{*}{11} & Right & 126 & 140 & $3.5(3.1)$ & $3.1(2,8)$ & 0.214 \\
\hline & Left & 126 & 140 & $3.7(3.2)$ & $3.2(2.7)$ & 0.214 \\
\hline
\end{tabular}




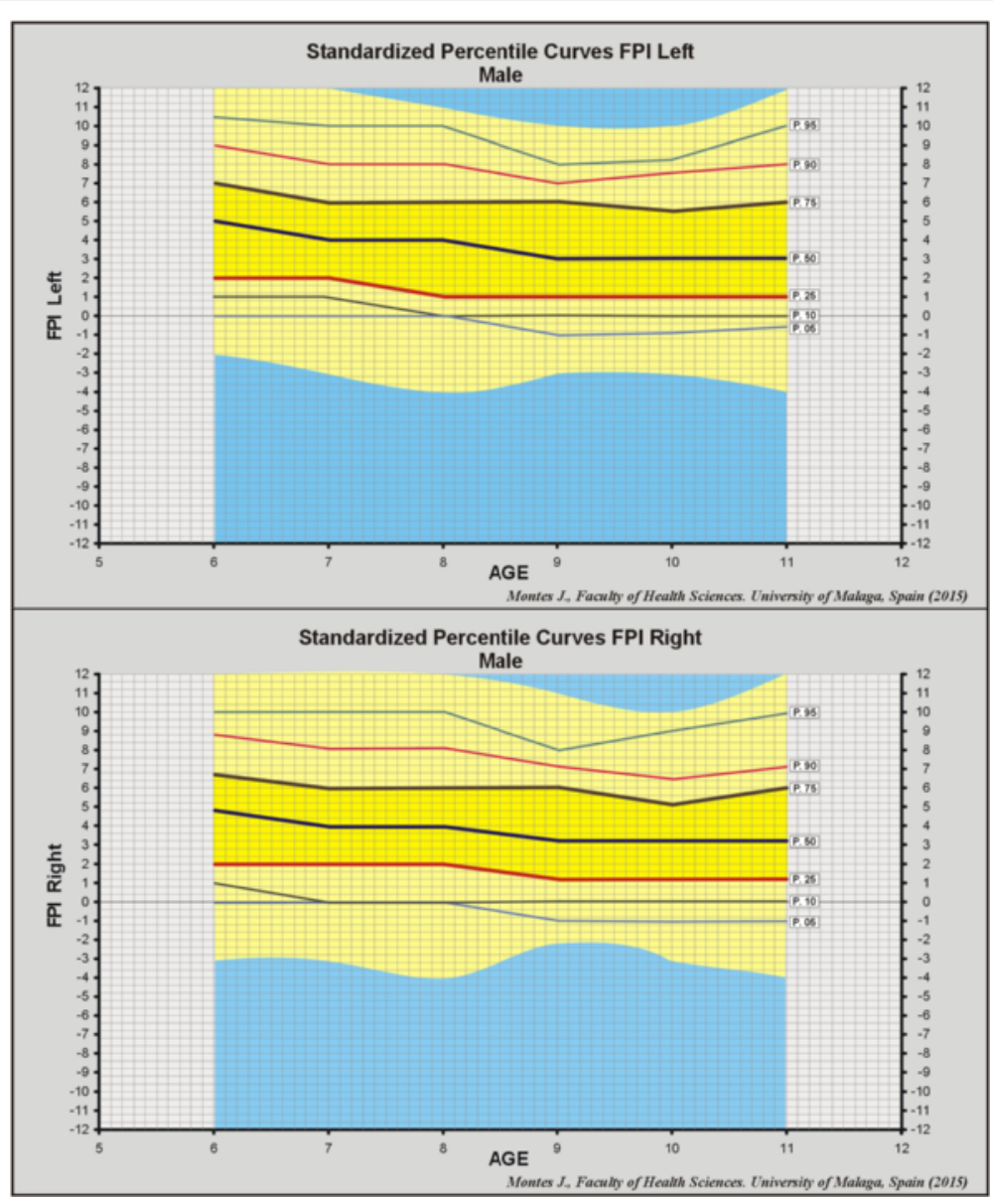

Fig. 1 Percentile curves left and right foot in males

As can be seen in the frequency graphs, FPI $=6$ is the normal value for both genders and for both feet in the total sample (Fig. 3).

In addition, the FPI of the z-score measurements was calculated. In this respect, the 50th percentile in both feet gave a FPI value of 4 (Table 4, Fig. 4). Following the criteria used by Redmond et al. [20], the 85th percentile was the boundary for the pronated foot, and the 4th percentile was that for the supinated foot.

The aim of this study was to establish normal values for FPI in the paediatric population, in relation to foot posture changes with growth. No significant differences between genders were recorded for FPI frequencies and percentiles (Figs. 1 and 2). The study population was composed of 1,762 school children (863 boys and 899). This sample size and distribution is similar to that used in a study to establish normal values for FPI in the general population [20], which featured 1,648 participants (717 men, 825 women and 116 unspecified gender). The mean FPI value reported in this study (3.82 points) was also consistent with that for the children in our study (3.72 points). A noteworthy finding was that of the FPI values for younger and older adults (2.4 and 2.9 points, respectively), which highlights the existence of a significant difference in foot posture between children and adults $(F=51.07, p<0.001)[20]$.

By gender, the mean FPI values were 3.96 and 3.67 points in boys and girls, respectively, which is within the generally-accepted margins of normal foot posture ( 0 to +5 points) $[20,22]$, and coincides with the results obtained in previous studies of FPI in children $[22,29]$. The value of the 85 th percentile of the FPI was approximately 6 points for both genders (Table 4 ). Pronation is generally assumed to be represented by FPI values of 6-9 points for moderate pronation, and of 9-12 points for severe pronation [22], and therefore the 85th percentile can be taken as a cutoff point between normal and pronation.

One of the most interesting findings of this study is the small degree of change between the ages of 6 and 8 years. In fact, a significant reduction in PAFF only occurred from the age of 9 years. This outcome may be associated with physical development, which would corroborate previous studies that have reported a 


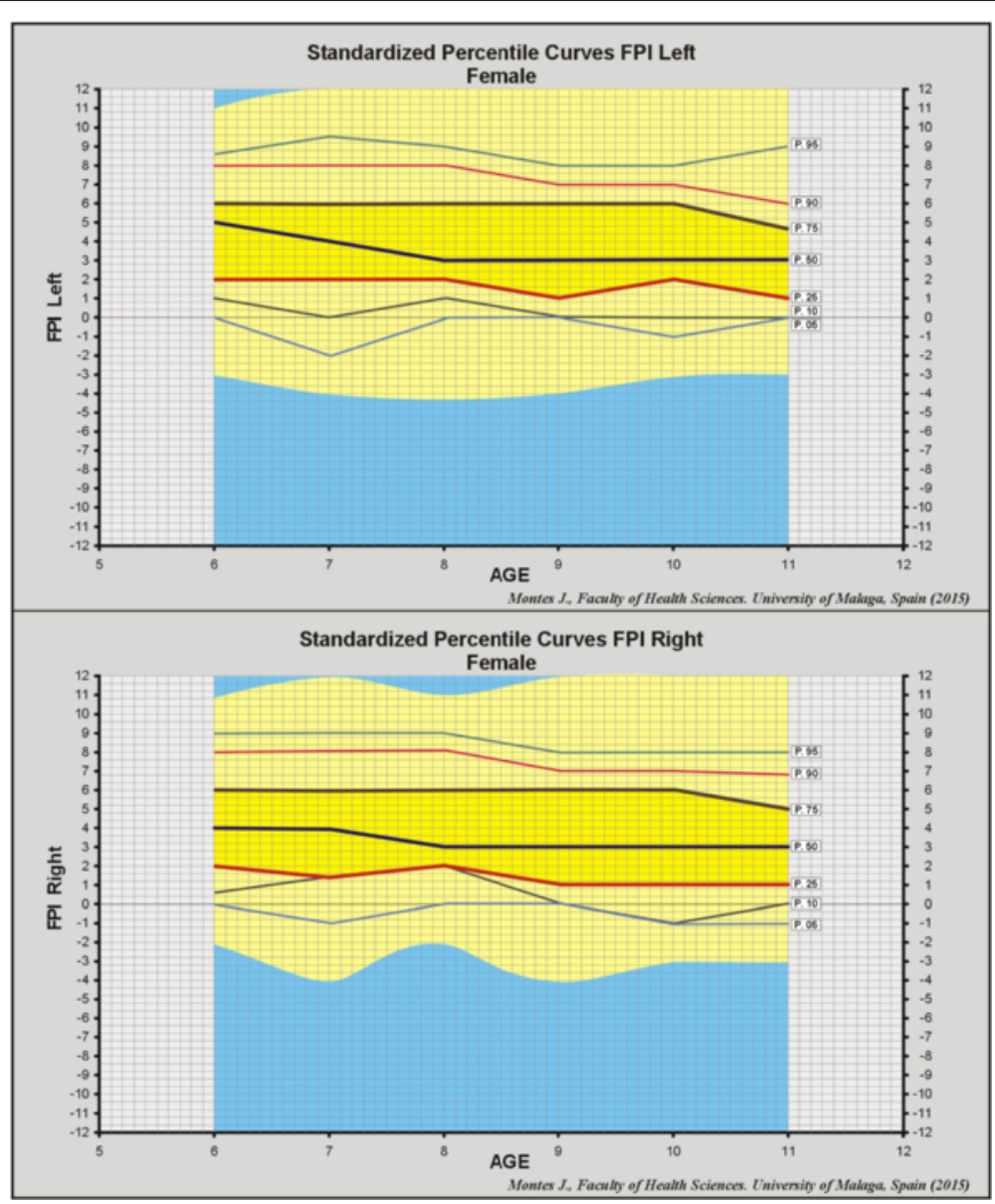

Fig. 2 Percentile curves left and right foot in females

reduction in the prevalence of PAFF with age, despite using other measurement techniques such as examination of the footprint, radiographic measurement of angles or observational techniques $[8,13,23-25,30]$. Our own study was based on observation of a large, multicentre and homogeneous sample, although restricted to a single country.

The main limitation of this study concerns the age of the subjects, who were only analysed up to age 11 years, a cutoff point determined by the fact that in Spain
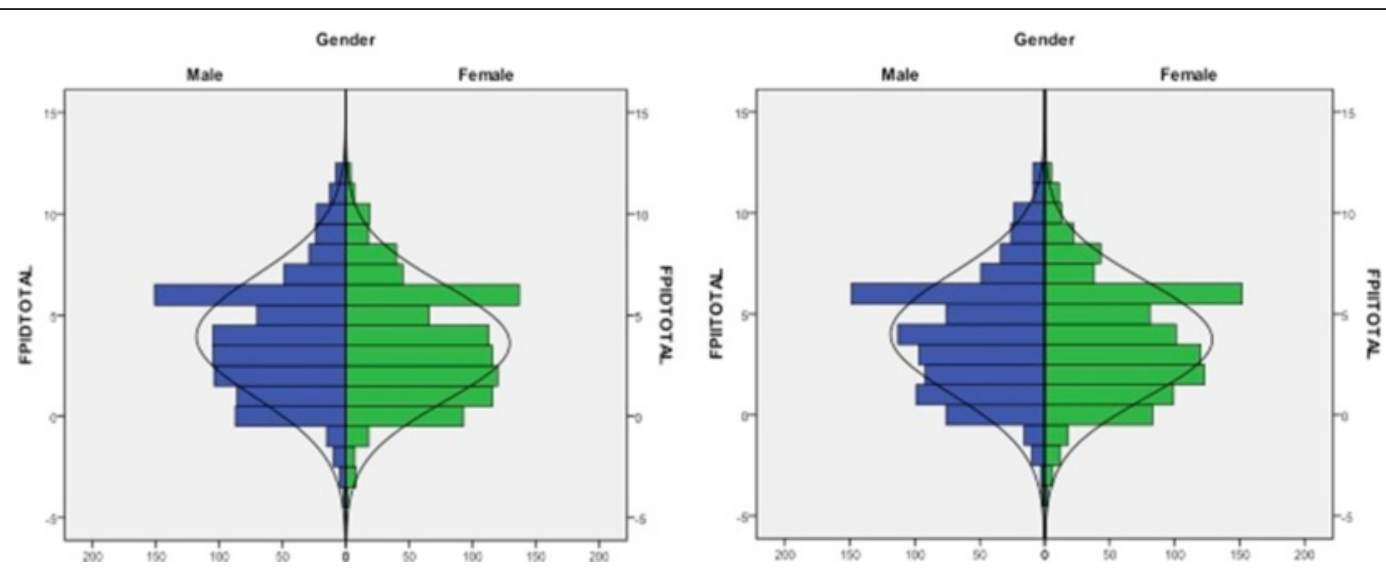

Fig. $3 \mathrm{FPI}$ frequencies in both sides and genders 
Table 4 Total FPI with z-score by laterality

\begin{tabular}{|c|c|c|c|c|c|c|}
\hline \multirow[b]{2}{*}{ value } & \multicolumn{3}{|l|}{ FPI Right } & \multicolumn{3}{|l|}{ FPI Left } \\
\hline & percentil & z & $T$ & percentil & z & $T$ \\
\hline-4 & 1 & -2.65 & 23.50 & .2 & -2.69 & 23.08 \\
\hline-3 & 1 & -2.31 & 26.91 & .7 & -2.35 & 26.50 \\
\hline-2 & 2 & -1.97 & 30.32 & 1.9 & -2.01 & 29.92 \\
\hline-1 & 4 & -1.63 & 33.73 & 3.8 & -1.67 & 33.34 \\
\hline 0 & 14 & -1.29 & 37.14 & 12.6 & -1.32 & 36.76 \\
\hline 1 & 25 & -0.94 & 40.55 & 23.5 & -0.98 & 40.18 \\
\hline 2 & 37 & -0.60 & 43.96 & 35.4 & -0.64 & 43.60 \\
\hline 3 & 49 & -0.26 & 47.37 & 47.3 & -0.30 & 47.02 \\
\hline 4 & 61 & 0.08 & 50.78 & 59.1 & 0.04 & 50.44 \\
\hline 5 & 69 & 0.42 & 54.19 & 67.8 & 0.39 & 53.86 \\
\hline 6 & 85 & 0.76 & 57.60 & 84.4 & 0.73 & 57.28 \\
\hline 7 & 90 & 1.10 & 61.01 & 89.2 & 1.07 & 60.70 \\
\hline 8 & 94 & 1.44 & 64.42 & 93.4 & 1.41 & 64.12 \\
\hline 9 & 96 & 1.78 & 67.84 & 96.1 & 1.75 & 67.54 \\
\hline 10 & 98 & 2.12 & 71.25 & 98.1 & 2.10 & 70.95 \\
\hline 11 & 99 & 2.47 & 74.66 & 99.2 & 2.44 & 74.37 \\
\hline 12 & 100 & 2.81 & 78.07 & 100 & 2.78 & 77.79 \\
\hline
\end{tabular}

children transfer from primary school to high school at this age. Ideally, our sample should have included subjects aged up to 18 years.

Future studies of this type, with similarly large sample sizes and a greater age range, taking into account different ethnic groups and geographic regions, could achieve greater precision regarding the reference values for foot posture in childhood and adolescence. Moreover, cohort studies of foot posture in childhood, using the FPI, would contribute to a better understanding of the development of the foot during growth.

Our study shows the FPI to be a good outcome measure for foot posture in the paediatric population, achieving a weighted Kappa value of $\mathrm{Kw}=0.88$ [22], good intra-observer correlation ( $\mathrm{ICC}=0.93-0.96)$ and good inter-observer reliability $(\mathrm{ICC}=0.79)$ [26]. This index has also been used successfully in studies based on subjects with diverse musculoskeletal pathologies $[27,31-33]$ and in studies of childhood obesity and its influence on foot posture [29, 34]. Furthermore, the FPI offers a three-dimensional assessment of pronation and supination, unlike traditional biplanar techniques such as footprint examination or radiography.

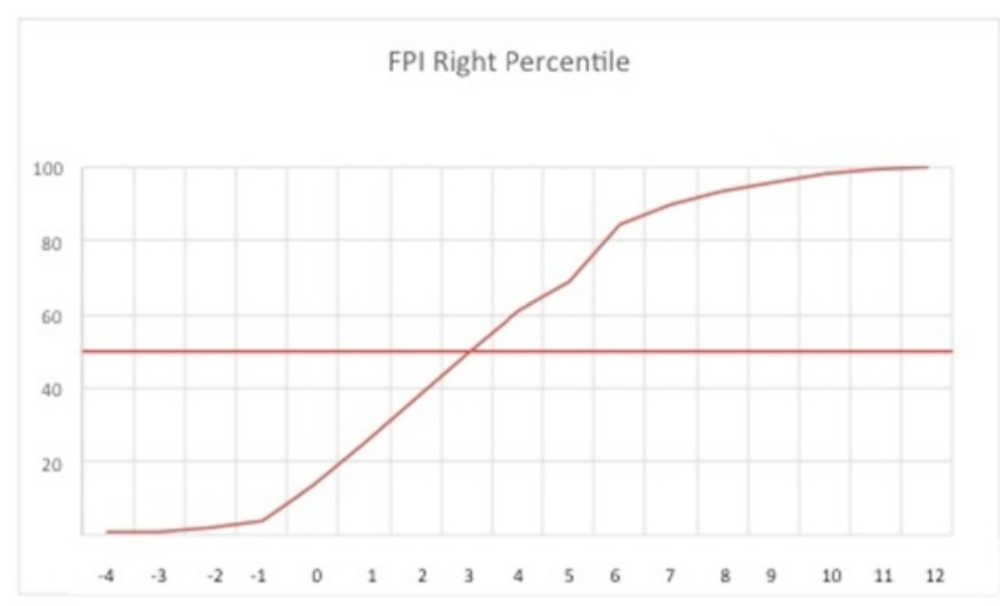

FPI Left Percentile

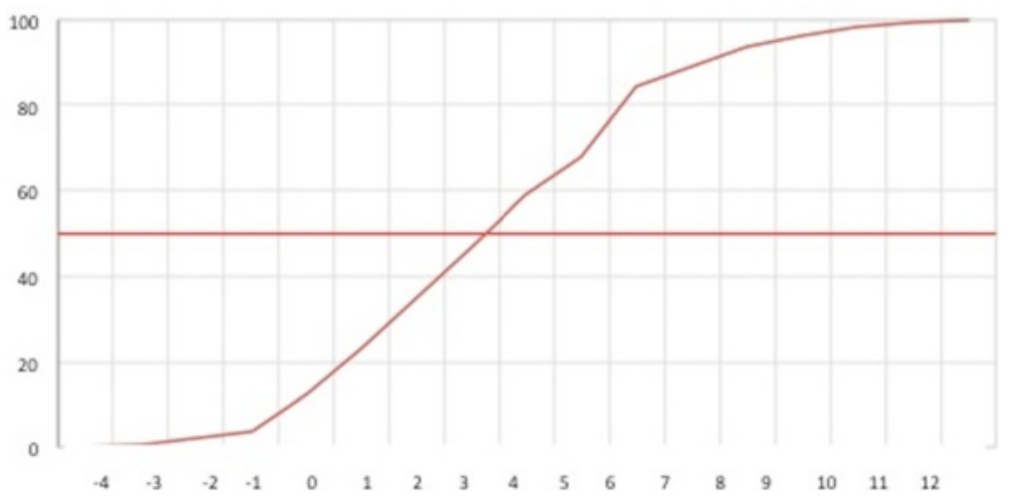

Fig. 4 Percentile curves left and right foot with $z$-scores 
The results obtained in this study enable us to establish reference foot posture values, based on the FPI, for a healthy paediatric population. The data are presented by percentiles, with mean values and the corresponding standard deviation, which we believe would be useful in future studies conducted to identify non-normal values, whether physiological or clinical, identified in foot-screening procedures similar to those used to determine the BMI. This approach could be of value in identifying subjects who need to be referred elsewhere for deeper analysis of gait or growth. These data can also be used, in conjunction with those provided by future studies of foot symptomatology, to better determine what should be considered physiological or pathological as regards foot posture in childhood. Our study, therefore, could be viewed as complementary to Redmond et al. [20], regarding normative values for the Foot Posture Index in children.

\section{Conclusions}

As limits for normative FPI values, we recommend the 85 th percentile for pronation and the 4th for supination. The 50th percentile is 4 points for children (both male and female) aged 6 years. This value falls progressively with age, to 3 FPI points for children aged 11 years.

\section{Abbreviations}

FPI, foot posture index; ICC, inter-correlation coefficient; PSFF, flatfoot and symptomatic flexible flatfoot

\section{Acknowledgements}

Not applicable.

\section{Funding}

The authors declare that they have no financial relationships relevant to this article to disclose.

\section{Availability of data and supporting materials}

At present, the data are not available to be shared because they form part of a joint project with another research group.

\section{Authors' contributions}

GNG contributed to the study's conception, design and analysis, and drafted the manuscript. MNA contributed to the study's conception, design and analysis, and drafted the manuscript. MAJ contributed to data acquisition. CMJA contributed to the study's conception and design. AGP contributed to data acquisition. MAJM contributed to the analysis and critically revised the manuscript. All authors read and approved the final manuscript.

\section{Competing interests}

The authors declare that they have no competing interests.

\section{Consent for publication}

Not applicable.

\section{Ethics approval and consent to participate}

This study was conducted in accordance with the Declaration of Helsinki and was approved by the Ethics Committees of the Universities of Extremadura and Málaga (Spain). The parents were previously informed about the characteristics of the study. They were all asked to complete a questionnaire and to provide signed consent to confirm the participation of their children in the study.

\section{Author details}

'Department of Nursing and Podiatry, Arquitecto Francisco Peñalosa 3, Malaga, Spain. ${ }^{2}$ Department of Nursing, University of Extremadura, Badajoz, Spain.

Received: 19 January 2016 Accepted: 12 July 2016

Published online: 26 July 2016

\section{References}

1. Bordelon RL. Hypermobile flatfoot in children. Comprehension, evaluation, and treatment. Clin Orthop. 1983;181:7-14.

2. Harris EJ. The natural history and pathophysiology of flexible flatfoot. Clin Podiatr Med Surg. 2010;27(1):1-23.

3. McCarthy DJ. The developmental anatomy of pes valgo planus. Clin Podiatr Med Surg. 1989;6(3):491-509.

4. Onodera AN, Sacco ICN, Morioka EH, Souza PS, de Sá MR, Amadio AC. What is the best method for child longitudinal plantar arch assessment and when does arch maturation occur? Foot Edinb Scotl. 2008;18(3):142-9.

5. Tareco JM, Miller NH, MacWilliams BA, Michelson JD. Defining flatfoot. Foot Ankle Int. 1999:20(7):456-60

6. Harris EJ, Vanore JV, Thomas JL, Kravitz SR, Mendelson SA, Mendicino RW, et al. Diagnosis and treatment of pediatric flatfoot. J Foot Ankle Surg Off Publ Am Coll Foot Ankle Surg. 2004;43(6):341-73

7. Evans AM, Nicholson $\mathrm{H}$, Zakarias $\mathrm{N}$. The paediatric flat foot proforma (p-FFP): improved and abridged following a reproducibility study. J Foot Ankle Res. 2009:2:25.

8. Staheli LT, Chew DE, Corbett M. The longitudinal arch. A survey of eight hundred and eighty-two feet in normal children and adults. J Bone Joint Surg Am. 1987;69(3):426-8.

9. Chen K-C, Yeh C-J, Kuo J-F, Hsieh C-L, Yang S-F, Wang C-H. Footprint analysis of flatfoot in preschool-aged children. Eur J Pediatr. 2011;170(5): 611-7.

10. Fascione JM, Crews RT, Wrobel JS. Association of footprint measurements with plantar kinetics: a linear regression model. J Am Podiatr Med Assoc. 2014:104(2):125-33.

11. Chang $\mathrm{C}-\mathrm{H}$, Chen $\mathrm{Y}-\mathrm{C}$, Yang W-T, Ho P-C, Hwang A-W, Chen C-H, et al. Flatfoot diagnosis by a unique bimodal distribution of footprint index in children. PLoS One. 2014;9(12):e115808.

12. Pauk J, Ihnatouski $M$, Najafi B. Assessing plantar pressure distribution in children with flatfoot arch: application of the Clarke angle. J Am Podiatr Med Assoc. 2014;104(6):622-32.

13. Villarroya MA, Esquivel JM, Tomás C, Moreno LA, Buenafé A, Bueno G. Assessment of the medial longitudinal arch in children and adolescents with obesity: footprints and radiographic study. Eur J Pediatr. 2009;168(5): 559-67.

14. Metcalfe SA, Bowling FL, Baltzopoulos V, Maganaris C, Reeves ND. The reliability of measurements taken from radiographs in the assessment of paediatric flat foot deformity. Foot Edinb Scotl. 2012;22(3):156-62.

15. Yocum A, McCoy SW, Bjornson KF, Mullens P, Burton GN. Reliability and validity of the standing heel-rise test. Phys Occup Ther Pediatr. 2010;30(3): 190-204. doi:10.3109/01942631003761380.

16. Vinicombe A, Raspovic A, Menz HB. Reliability of navicular displacement measurement as a clinical indicator of foot posture. J Am Podiatr Med Assoc. 2001;91(5):262-8.

17. Picciano AM, Rowlands MS, Worrell T. Reliability of open and closed kinetic chain subtalar joint neutral positions and navicular drop test. J Orthop Sports Phys Ther. 1993;18(4):553-8.

18. Kothari A, Dixon PC, Stebbins J, Zavatsky AB, Theologis T. Motion analysis to track navicular displacements in the pediatric foot: relationship with foot posture, body mass index, and flexibility. Foot Ankle Int. 2014;35(9):929-37.

19. Redmond AC, Crosbie J, Ouvrier RA. Development and validation of a novel rating system for scoring standing foot posture: the Foot Posture Index. Clin Biomech (Bristol, Avon). 2006;21(1):89-98.

20. Redmond AC, Crane YZ, Menz HB. Normative values for the Foot Posture Index. J Foot Ankle Res. 2008;1(1):6.

21. Lee JS, Kim KB, Jeong JO, Kwon NY, Jeong SM. Correlation of foot posture index with plantar pressure and radiographic measurements in pediatric flatfoot. Ann Rehabil Med. 2015;39(1):10-7.

22. Morrison SC, Ferrari J. Inter-rater reliability of the Foot Posture Index (FPI-6) in the assessment of the paediatric foot. J Foot Ankle Res. 2009;2:26. 
23. García-Rodríguez A, Martín-Jiménez F, Carnero-Varo M, Gómez-Gracia E, Gómez-Aracena J, Fernández-Crehuet J. Flexible flat feet in children: a real problem? Pediatrics. 1999;103(6):e84.

24. El O, Akcali O, Kosay C, Kaner B, Arslan Y, Sagol E, et al. Flexible flatfoot and related factors in primary school children: a report of a screening study. Rheumatol Int. 2006;26(11):1050-3.

25. Pfeiffer M, Kotz R, Ledl T, Hauser G, Sluga M. Prevalence of flat foot in preschool-aged children. Pediatrics. 2006;118(2):634-9.

26. Evans AM, Rome $K$, Peet $L$. The foot posture index, ankle lunge test, Beighton scale and the lower limb assessment score in healthy children: a reliability study. J Foot Ankle Res. 2012;5(1):1.

27. Barton CJ, Bonanno D, Levinger $P$, Menz HB. Foot and ankle characteristics in patellofemoral pain syndrome: a case control and reliability study. J Orthop Sports Phys Ther. 2010;40(5):286-96.

28. Redmond AC. The Foot Posture Index. User guide and manual [Manual available online]. Leeds: University of Leeds; 2005.

29. Evans $\mathrm{AM}$. The paediatric flat foot and general anthropometry in 140 Australian school children aged 7-10 years. J Foot Ankle Res. 2011;4(1):12.

30. Gould N, Moreland M, Alvarez R, Trevino S, Fenwick J. Development of the child's arch. Foot Ankle. 1989;9(5):241-5.

31. Kennedy J, Noel J, O'Meara A, Kelly P. Foot and ankle abnormalities in the Hurler syndrome: additions to the phenotype. J Pediatr Orthop. 2013;33(5): 558-62.

32. James AM, Williams CM, Luscombe M, Hunter R, Haines TP. Factors associated with pain severity in children with calcaneal apophysitis (Sever Disease). J Pediatr. 2015:167(2):455-9.

33. Williams C, Tinley PD, Curtin M, Nielsen S. Foot and ankle characteristics of children with an idiopathic toe-walking gait. J Am Podiatr Med Assoc. 2013: 103(5):374-9.

34. Tucker J, Moore M, Rooy J, Wright A, Rothschild C, Werk LN. Reliability of common lower extremity biomechanical measures of children with and without obesity. Pediatr Phys Ther. 2015;27(3):250-6. doi:10.1097/PEP. 0000000000000152

\section{Submit your next manuscript to BioMed Central and we will help you at every step:}

- We accept pre-submission inquiries

- Our selector tool helps you to find the most relevant journal

- We provide round the clock customer support

- Convenient online submission

- Thorough peer review

- Inclusion in PubMed and all major indexing services

- Maximum visibility for your research

Submit your manuscript at www.biomedcentral.com/submit

C Biomed Central 